\title{
Preventable hospitalizations from ambulatory care sensitive conditions in nursing homes: evidence from Switzerland
}

\author{
Ulrike Muench ${ }^{1} \cdot$ Michael Simon $^{2,3} \cdot$ Raphaëlle-Ashley Guerbaai $^{2} \cdot$ Carlo De Pietro $^{4} \cdot$ Andreas Zeller $^{5,6}$. \\ Reto W. Kressig ${ }^{5,7}$ - Franziska Zúñiga ${ }^{2}$ (i) · For the INTERCARE Research Group
}

Received: 17 October 2018/Revised: 24 August 2019/Accepted: 27 August 2019/Published online: 3 September 2019

(c) The Author(s) 2019

\begin{abstract}
Objectives Reducing nursing home hospitalizations for ambulatory care sensitive conditions (ACSC) has been identified as an opportunity to improve patient well-being and reduce costs. The aim of this study was to identify number of hospitalizations for ACSCs for nursing home residents in a Swiss national sample, examine demographic characteristics of nursing home hospitalizations due to ACSCs, and calculate hospital expenses from these hospitalizations.

Methods Using merged hospital administrative data with payment data based on diagnosis-related groups (DRGs) for the year 2013, we descriptively examined nursing home residents who were 65 years of age or older and were admitted to an acute care hospital.

Results Approximately $42 \%$ of all nursing home admissions were due to ACSCs. Payments to Swiss hospitals for ACSCs can be estimated at between 89 and 105 million Swiss francs in 2013.

Conclusions A sizable share of hospitalizations for nursing home residents is for ACSCs, and the associated costs are substantial. Programs and policies designed to reduce these potentially avoidable hospitalizations from the nursing home setting could lead to an increased patient well-being and lower costs.
\end{abstract}

Keywords Avoidable hospitalizations $\cdot$ Hospital costs $\cdot$ Nursing homes $\cdot$ Preventable hospitalizations

Electronic supplementary material The online version of this article (https://doi.org/10.1007/s00038-019-01294-1) contains supplementary material, which is available to authorized users.

Franziska Zúñiga

franziska.zuniga@unibas.ch

1 Department of Social and Behavioural Sciences, University of California San Francisco, School of Nursing, San Francisco, USA

2 Department of Public Health, Institute of Nursing Science, Faculty of Medicine, University of Basel, Bernoullistr. 28, 4056 Basel, Switzerland

3 Nursing and Midwifery Research Unit, Inselspital Bern University Hospital, Bern, Switzerland

4 Department of Business Economics, Health and Social Care at the University of Applied Sciences and Arts of Southern Switzerland, Lugano, Switzerland

5 Faculty of Medicine, University of Basel, Basel, Switzerland

6 Center for Primary Health Care, University of Basel, Basel, Switzerland

7 FELIX PLATTER, University Medicine of Aging, Basel, Switzerland

\section{Introduction}

Reducing preventable hospitalizations of nursing home residents is important to the health and well-being of nursing home residents (Ouslander and Maslow 2012; Walsh et al. 2012). Hospitalizations of frail, elderly persons with multiple chronic conditions are often related to loss of functional ability, delirium, cognitive decline, falls, hospital-acquired infections, and discontinuity of medications (Boockvar et al. 2004; Dwyer et al. 2014; Palese et al. 2016; Zisberg et al. 2016). Several estimates show that in the USA and Canada, between 20 and $60 \%$ of hospitalizations from nursing homes are considered preventable (Mcandrew et al. 2016; Ouslander et al. 2010; Walker et al. 2009; Walsh et al. 2012). These hospitalizations are not only a major burden to residents but also a substantial financial burden to the health-care delivery system, with the costs of a hospitalization averaging between $\$ 8000$ and $\$ 20,000$ in the USA (Axon et al. 2015; Grabowski et al. 2007; Mcandrew et al. 2016; Walsh et al. 2010; Xing et al. 2013). 
Preventable-avoidable, inappropriate, or unnecessary-hospitalizations fall into two groups: hospitalizations which could have been avoided with evidence-based, chronic disease management, prevention of acute deteriorations of chronic conditions, or hospitalizations for conditions which could have been treated in the nursing home. Ambulatory care sensitive conditions (ACSCs) are a group of conditions which include pneumonia, chronic obstructive pulmonary disease (COPD), or congestive heart failure (CHF), among others, and are one of the approaches to measure preventability. Research conducted in the USA suggests that this set of conditions can be effectively and safely managed in the primary care setting when early detection and adequate chronic disease management are in place (Mcandrew et al. 2016; Walsh et al. 2012). Identifying ACSCs can serve as an approximation of potentially preventable hospitalizations, although the effective management of these conditions outside the hospital setting depends on a variety of factors. For example, the decision for or against an ED visit or hospitalization is guided by residents' and families' preferences, the presence of advance care planning, do-not hospitalize and do-not resuscitate orders, timely availability of qualified staff, availability of diagnostic and therapeutic interventions in the nursing home, and the acuteness and severity of the condition (Ouslander and Maslow 2012; Renom-Guiteras et al. 2014). Finally, reimbursement policies might favor hospitalizations (Ashton 2014).

ACSCs were developed for the primary care setting and have been used for both research and policy analysis (Billings et al. 1993; Purdy et al. 2009; Weissman et al. 1992). Several approaches exist in the literature as to which conditions are considered sensitive to ambulatory care (Ansari et al. 2012; Billings et al. 1993; Millman 1993; Purdy et al. 2009; Weissman et al. 1992). Recently, expert panels in the USA and Canada developed groups of conditions specifically for nursing home residents (Walker et al. 2009; Walsh et al. 2012). While there were some inconsistencies in the groups of ACSCs identified, consensus was reached regarding the inclusion of asthma, cellulitis, CHF, COPD, dehydration, gastroenteritis, diabetes complications, hypertension, pneumonia, urinary tract infection (UTI), seizures, and injuries from falls/ fractures. Typically, in case of exacerbation of any of these conditions, many residents would need to be treated in the hospital. However, preventing ACSCs is achieved through effective monitoring of resident symptoms in nursing homes, in combination with an interprofessional approach to discuss treatment goals and procedures, to avoid exacerbations when possible. For example, in case of an acute situation, the resident might remain in the nursing home for palliative care. Similarly, residents with a tentative diagnosis of fracture will go to the ED; however, an effective fall management program might prevent fall-related injuries.

While ACSCs do not capture all the factors which contribute to a decision to hospitalize a resident, identifying ACSCs and understanding resident characteristics that are associated with an ACSC can provide valuable insight into whether nursing home residents are or are not receiving high-quality care. The Center for Medicare and Medicaid (CMS), the Agency for Healthcare Research and Quality (AHRQ), the WHO, and the OECD are using ACSCs hospitalizations as quality indicators (OECD 2015; WHO Regional Office for Europe 2016). Thus, identifying hospitalizations that are potentially preventable can provide valuable information for hospital and nursing home administrators, policy makers, and researchers.

The aim of this paper is threefold: to identify ACSCs hospitalizations in Swiss hospitals that are from nursing homes, examine patient characteristics associated with ACSCs, and calculate hospital payments for ACSCs.

\section{Methods}

\section{Design, setting, and sample}

This study is a retrospective descriptive analysis of nursing home residents' admissions to hospitals in Switzerland for the year 2013. Our sample consisted of patients aged 65 and older with at least one admission to an acute care hospital. Admissions to psychiatric hospitals were excluded. Figure 1 shows the sample selection process.

\section{Data}

We used data from two different sources: (1) administrative claims from the Medical Statistics of Hospitals (Medizinische Statistik der Krankenhäuser), kept by the Swiss Federal Statistical Office (SFSO), and (2) data on hospital payments for diagnosis-related groups (DRGs) kept by SwissDRG AG (SwissDRG AG 2012). All hospitals in Switzerland are mandated to collect data for every hospitalization and report them yearly to the SFSO (Bundesamt für Statistik). In addition to indicating whether patients had a hospital admission, these data included information on demographics, patient diagnoses, DRGs, length of stay, and discharge location, among other factors. For the purpose of our analysis, we made use of the DRG codes available in both data sets to merge these sources and calculate the costs per admission (more detail below). All data in the Medical Statistics of Hospitals are routinely collected and are de-identified. No ethics approval was necessary. 
Fig. 1 Flowchart of the sample selection process

\section{All Hospitalizations in 2013}

$(\mathrm{N}=1,374,439)$

Excluded

$N=64,058$

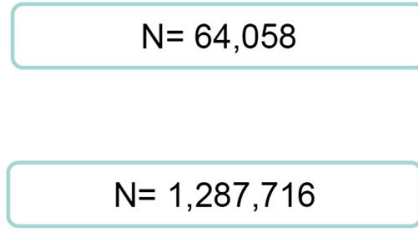

$N=3,456$

$N=595$

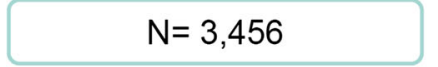

$N=595$

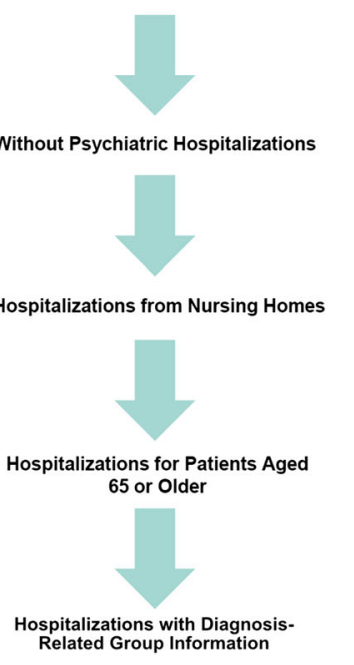

Included

$N=1,310,381$

$N=22,665$

$N=19,209$

$\mathrm{N}=18,614$

\section{Measures}

\section{Primary outcomes}

Hospitalizations related to ACSC We measured the number of hospitalizations for patients who were admitted with ACSCs. ACSCs were identified based on conditions recognized as being sensitive to nursing home care, by the CMS in the USA (Walsh et al. 2010) and by researchers in Canada (Walker et al. 2009). Since the two lists differed, we used conditions which were included in both lists: asthma, poor glycemic control, hypertension, cellulites, dehydration, diarrhea, seizures, UTI, COPD, CHF, pneumonia and bronchitis, falls, and trauma. As these conditions were identified with ICD-9 codes originally, we applied the corresponding Swiss ICD-10 codes [15] (see supplementary material for full list). In case of coding discrepancies (e.g., which codes were attributed to identifying COPD), we followed the ACSC identification outlined by Walsh and colleagues (Walsh et al. 2010).

Costs related to ACSCs Hospital payments in Switzerland are calculated based on cost weights. Cost weights are determined according to the SwissDRG classification system. Each DRG has a cost weight (adjusted annually based on hospital costs). We used this cost weight and multiplied it with a base rate (negotiated between insurers and hospitals). For our study, we used a base rate of 11,200 CHF for university hospitals and $9200 \mathrm{CHF}$ for non-university hospitals, to provide a range of costs attributable to ACSC hospitalizations, because we did not have access to regional information on hospital admissions. This would have allowed us to use more detailed regional base rates for each Canton. In addition, cost weights were adjusted with a predetermined weight for every day a patient's length of stay fell below or above a certain threshold (SwissDRG AG 2012). For the purpose of our analysis, we did not apply supplementary payments under SwissDRG version 2.0, and did not include supplementary payments for blood transfusions under SwissDRG version 2.0. For a more detailed description of hospital payments, DRGs, and cost weights, see SwissDRG AG (SwissDRG AG). We excluded hospitalizations for which a DRG weight was not available; this was the case for approximately $3 \%$ of the sample (see Fig. 1).

\section{Statistical analysis}

Descriptive analyses were performed based on the distribution of the variables (frequencies and percentages, median, and interquartile range).

\section{Results}

\section{Sample characteristics}

Overall, there were $1,374,439$ hospitalizations in Swiss hospitals, in 2013, of which 64,058 (4.7\%) were to a psychiatric hospital. Of the remaining acute care hospitalizations, $85.6 \%$ of patients were admitted from home, $8.8 \%$ from other hospitals, $1.7 \%$ from nursing homes, and $3.9 \%$ from other settings. When focusing on nursing home admissions, there were a total of 19,209 hospitalizations of 
patients 65 years and older. We combined data from these patients with their available DRG data. A small number of hospitalizations (3\%) did not have DRG information that matched with our DRG database. The final analytic sample that met our sample selection criteria outlined in Fig. 1, consisted of 18,614 hospitalizations belonging to 16,215 patients.

Patients were admitted between 1 and 8 times, and $18.1 \%$ (3370) of patients had multiple hospitalizations, representing $11 \%$ (2002) of the total share of hospitalizations observed in 2013. Table 1 shows the age and gender breakdown for ACSCs versus other conditions. While over half of all hospitalizations were from patients 80 years or older regardless of ACSC status, the shares of hospitalizations for ACSCs were considerably larger for patients 85-90 years of age (26.3\% non-ACSC vs. $29.3 \%$ ACSC) and for patients $90-95$ years of age (15.1\% non-ACSC vs. $22.1 \%$ ACSC). Women were hospitalized more for ACSCs than for non-ACSCs, while men were less hospitalized for ACSCs.

Table 2 summarizes entry and exit information related to each hospitalization, including mode of admission (self/family, ambulance, physician, other) and the place of discharge. While more residents were admitted for ACSCs than non-ACSCs with an ambulance ( $41.8 \%$ vs. $30.7 \%)$, it was the other way round for admissions by a physician (45.7\% ACSCs vs. 59.2\% non-ACSCs). Approximately two-thirds of hospitalizations were associated with discharges to nursing homes regardless of ACSC status. The share of hospitalizations that were associated with in-hospital mortality was $8.8 \%$ for non-ACSCs and $6.9 \%$ for ACSCs.
Table 2 Entry and discharge information associated with hospitalization by ambulatory care sensitive condition status (Swiss Federal Office of Statistics, 2013), Switzerland 2013

\begin{tabular}{|c|c|c|c|c|}
\hline & \multicolumn{2}{|c|}{$\begin{array}{l}\text { Non-ACSC } \\
(n=10,679)\end{array}$} & \multicolumn{2}{|c|}{$\begin{array}{l}\text { ACSC } \\
(n=7935)\end{array}$} \\
\hline & $n$ & $\%$ & $n$ & $\%$ \\
\hline \multicolumn{5}{|l|}{ Admitted by } \\
\hline Self or family & 610 & 5.7 & 569 & 7.2 \\
\hline Ambulance & 3276 & 30.7 & 3313 & 41.8 \\
\hline Physician & 6326 & 59.2 & 3626 & 45.7 \\
\hline Other & 467 & 4.4 & 427 & 5.4 \\
\hline \multicolumn{5}{|c|}{ Place of stay after discharge } \\
\hline Death & 937 & 8.8 & 548 & 6.9 \\
\hline Home & 2232 & 20.9 & 1188 & 15.0 \\
\hline Nursing home & 6465 & 60.5 & 5470 & 68.9 \\
\hline Other & 1045 & 9.8 & 729 & 9.2 \\
\hline
\end{tabular}

ACSC ambulatory care sensitive condition

\section{Potentially avoidable hospitalizations for ambulatory care sensitive conditions}

Approximately $42 \%$ of hospitalizations from nursing home residents were attributable to an ACSC. The three most common ACSCs were falls and trauma (53.6\%), pneumonia and bronchitis (15\%), and CHF (12.1\%). Pneumonia and bronchitis, $\mathrm{CHF}$, and poor glycemic control were also among the three most common conditions for in-hospital mortality. Table 3 shows the proportions of ACSCs as share of total nursing home hospitalizations by hospital mortality and length of stay.
Table 1 Demographic characteristics associated with hospitalizations by ambulatory care sensitive condition status (Swiss Federal Office of Statistics, hospital data 2013), Switzerland 2013

\begin{tabular}{|c|c|c|c|c|c|c|}
\hline & \multicolumn{2}{|c|}{ Non-ACSC $(n=10,679)$} & \multicolumn{2}{|c|}{$\operatorname{ACSC}(n=7935)$} & \multicolumn{2}{|c|}{ All admissions $(n=18,614)$} \\
\hline & $n$ & $\%$ & $n$ & $\%$ & $n$ & $\%$ \\
\hline \multicolumn{7}{|c|}{ Age groups } \\
\hline $65-69$ & 747 & 7.0 & 356 & 4.5 & 1103 & 5.9 \\
\hline $70-74$ & 1048 & 9.8 & 491 & 6.2 & 1539 & 8.3 \\
\hline $75-79$ & 1647 & 15.4 & 861 & 10.9 & 2508 & 13.5 \\
\hline $80-84$ & 2427 & 22.7 & 1610 & 20.3 & 4037 & 21.7 \\
\hline $85-89$ & 2808 & 26.3 & 2324 & 29.3 & 5132 & 27.6 \\
\hline $90-94$ & 1615 & 15.1 & 1755 & 22.1 & 3370 & 18.1 \\
\hline $95+$ & 387 & 3.6 & 538 & 6.8 & 925 & 5.0 \\
\hline \multicolumn{7}{|l|}{ Gender } \\
\hline Men & 3900 & 36.5 & 2354 & 29.7 & 6254 & 33.6 \\
\hline Women & 6779 & 63.5 & 5581 & 70.3 & 12360 & 66.4 \\
\hline
\end{tabular}

ACSC ambulatory care sensitive condition 
Table 3 Share of ambulatory care sensitive condition hospitalizations by diagnosis group, mortality, and length of stay (Swiss Federal Office of Statistics, 2013), Switzerland 2013

\begin{tabular}{|c|c|c|c|c|c|c|}
\hline \multirow[t]{2}{*}{ Ambulatory care sensitive condition } & \multicolumn{2}{|c|}{ Main diagnosis $(n=7935)$} & \multicolumn{2}{|c|}{ Mortality ( $n=548$ deaths) } & \multicolumn{2}{|c|}{ Length of stay $(n=7935)$} \\
\hline & $n$ & $\%^{\mathrm{a}}$ & $n$ & $\%^{\mathrm{b}}$ & Median & IQR \\
\hline Falls and trauma & 4253 & 22.8 & 214 & 5.0 & 8 & 8 \\
\hline Pneumonia and bronchitis & 1188 & 6.4 & 162 & 13.6 & 8 & 6 \\
\hline Congestive heart failure & 961 & 5.2 & 115 & 12.0 & 9 & 7 \\
\hline Urinary tract infection & 402 & 2.2 & 8 & 2.0 & 7 & 5 \\
\hline Chronic obstructive pulmonary disease & 391 & 2.1 & 20 & 5.1 & 8 & 7 \\
\hline Diarrhea and gastroenteritis & 285 & 1.5 & 6 & 2.1 & 7 & 6 \\
\hline Seizures & 207 & 1.1 & 12 & 5.8 & 6 & 7 \\
\hline Dehydration & 73 & 0.4 & 5 & 6.8 & 7 & 5 \\
\hline Hypertension & 68 & 0.4 & 1 & 1.5 & 6 & 5 \\
\hline Cellulitis & 49 & 0.3 & 1 & 2.0 & 9 & 9 \\
\hline Asthma & 29 & 0.2 & 0 & 0.0 & 7 & 5 \\
\hline Poor glycemic control & 29 & 0.2 & 4 & 13.8 & 7 & 7 \\
\hline Total & 7935 & 42.8 & 548 & 6.9 & & \\
\hline
\end{tabular}

$I Q R$ Interquartile range

${ }^{\text {a }}$ Percentage in relation to all hospitalizations $(n=18,614)$

${ }^{\mathrm{b}}$ Percentage in relation to each ambulatory care sensitive condition

\section{Costs associated with avoidable hospitalizations for ambulatory care sensitive conditions}

Assuming a base rate for university hospitals of 11,200 $\mathrm{CHF}$ and a base rate for non-university hospitals of 9500 $\mathrm{CHF}$, the average cost for an ACSC hospitalization in a university hospital was 13,267 CHF and 11,253 CHF for a non-university hospital, respectively. Costs ranged from 6704/5686 CHF (university/non-university hospitals) for UTIs to $15,332 / 13,005 \mathrm{CHF}$ (university/non-university hospitals) for falls and trauma. The three most common ACSCs, namely falls and trauma, pneumonia and bronchitis, and CHF, were among the five most expensive hospitalizations. Table 4 shows the average costs per hospitalization for each ACSC.

Hospital payments in 2013 for nursing home residents who were admitted with an ACSC totaled roughly 105 million CHF for a university hospital and 89 million CHF for non-university hospitals. In comparison, hospital costs for all conditions for nursing home residents combined were approximately 265 million $\mathrm{CHF}$ and 225 million CHF, respectively, for the two different base rates. Thus, the share of the costs associated with ACSCs was approximately $40 \%$ of the costs from all conditions. Aligned with the number of hospitalizations observed for each of the ACSCs, falls and trauma, pneumonia and bronchitis, and CHF were responsible for the highest hospital costs. Table 5 provides an overview of the costs for each ACSC and all other conditions for both university and non-university hospital base rates.

\section{Discussion}

Hospitalizations of nursing home residents who were admitted with an ACSC were frequent and expensive for the Swiss health-care system. We observed approximately $42 \%$ of nursing home admissions due to an ACSC, half of which were attributable to falls and trauma. These findings are similar to study reports from the USA, Canada, and Sweden, where the prevalence of ACSCs excluding falls ranged between 16 and 38\% (Grabowski et al. 2007; Kirsebom et al. 2014; McAndrew et al. 2015) and between 40 and 55\% for studies including falls (Walker et al. 2009; Walsh et al. 2012). Our results were also similar to findings from a Swedish study documenting $25 \%$ of ED visits due to falls from nursing home residents (Kirsebom et al. 2014). In contrast, Ouslander et al. found that $67 \%$ of hospitalizations were avoidable, without considering falls, using a structured review of medical charts by experts (Ouslander et al. 2010).

Results for our cost analysis showed that admissions for ACSCs were rather costly, ranging between 105 million CHF and 89 million CHF assuming base rates of 11,200 $\mathrm{CHF}$ and $9500 \mathrm{CHF}$, respectively. This constitutes approximately $40 \%$ of the total costs for all nursing home 
Table 4 Mean admission costs by ambulatory care sensitive conditions (Swiss Federal Office of Statistics, hospital data 2013), Switzerland 2013
Mean admission costs based on university

hospital rate

(11,200 CHF)
Mean admission costs based on non-university hospital rate (9500 CHF)

\begin{tabular}{lrc}
\hline Falls & 15,333 & 13,005 \\
Congestive heart failure & 13,013 & 11,038 \\
Seizures & 12,998 & 11,025 \\
Cellulitis & 12,683 & 10,758 \\
Pneumonia and bronchitis & 11,429 & 9694 \\
Chronic obstructive pulmonary disease & 10,768 & 9133 \\
Dehydration & 9589 & 8134 \\
Poor glycemic control & 8735 & 7409 \\
Hypertension & 7651 & 6490 \\
Asthma & 7368 & 6249 \\
Diarrhea and gastroenteritis & 7289 & 6183 \\
Urinary tract infection & 6704 & 5687 \\
\hline
\end{tabular}

Table 5 Hospital expenditures for ambulatory care sensitive conditions and all conditions (Swiss Federal Office of Statistics, hospital data 2013), Switzerland 2013

\begin{tabular}{lcc}
\hline & $\begin{array}{l}\text { Expenditures } \\
\text { based on university } \\
\text { hospital rate } \\
(11,200 \mathrm{CHF})\end{array}$ & $\begin{array}{c}\text { Expenditures based } \\
\text { on non-university } \\
\text { hospital rate } \\
(9500 \mathrm{CHF})\end{array}$ \\
\hline Falls & $65,210,208$ & $55,312,232$ \\
Pneumonia and bronchitis & $13,577,547$ & $11,516,670$ \\
Congestive heart failure & $12,505,483$ & $10,607,329$ \\
Chronic obstructive pulmonary disease & $4,210,158$ & $3,571,116$ \\
Urinary tract infection & $2,695,157$ & $2,286,070$ \\
Seizures & $2,690,621$ & $2,282,223$ \\
Diarrhea and gastroenteritis & $2,077,342$ & $1,762,032$ \\
Dehydration & 700,000 & 593,750 \\
Cellulitis & 621,454 & 527,126 \\
Hypertension & 520,274 & 441,304 \\
Poor glycemic control & 253,310 & 214,862 \\
Asthma & 213,662 & 181,232 \\
Total ambulatory care sensitive conditions & $105,275,216$ & $89,295,946$ \\
Other & $159,449,664$ & $135,247,488$ \\
Total & $264,724,880$ & $224,543,434$ \\
\hline
\end{tabular}

CHF Swiss francs admissions. The three most common ACSCs in our datafalls and trauma, pneumonia and bronchitis, and CHFhave also been reported to be among the top five conditions in other studies (Grabowski et al. 2007; McAndrew et al. 2015; Walker et al. 2009; Walsh et al. 2012; Xing et al. 2013). These common causes were also the most expensive, increasing the overall spending on ACSCs.
Interestingly, dehydration, a prevalent problem in several US studies, was less prevalent in our data. This might be due to coding differences or different care practices regarding the handling of hydration in Swiss nursing homes.

We found that $40 \%$ of the costs of all hospitalizations for nursing home residents are potentially avoidable and 
given that the Swiss health-care system ranks above the US health-care system, this is concerning. However, it also suggests that some areas in health-care delivery could be improved. For example, falls can be prevented with measures minimizing fall risks (Walsh et al. 2012). As shown in a review, multifactorial interventions led by an interprofessional team are able to reduce both the number of fallers and recurrent fallers (Vlaeyen et al. 2015). One core problem in the management of falls in nursing homes is ruling out the diagnosis of fracture, since hardly any nursing homes have the infrastructure to run the diagnostic procedures necessary. An interesting development to counter this is mobile X-rays with telemedicine for nursing homes, which might change diagnostic procedures and reduce burdensome and costly transfers to the ED (Kjelle and Lysdahl 2017) due to the possibility of X-rays within nursing homes, reducing unnecessary ED admissions.

Staffing and skill mix is another central component to decreasing ambulatory care sensitive hospitalizations. The idea behind the development of ACSCs was that timely and effective access to ambulatory care could prevent hospitalizations (Bindman et al. 1995; Weissman et al. 1992). If residents at risk for conditions such as COPD or CHF were well monitored, some episodes of exacerbations might be avoided or detected early enough to be managed in the nursing home, although this does not apply for severe bronchospasm or hemodynamic instability for instance (Walsh et al. 2010). Similarly, early identification and treatment of pneumonia and bronchitis could prevent a hospital stay (Walsh et al. 2010). Early identification and timely intervention requires nursing home staff with the geriatric expertise able to recognize changes and act upon observations. Several studies from the USA show that the use of advanced practice nurses (APNs) reduces preventable hospitalizations (Bakerjian 2008; Kane et al. 2003; Ouslander et al. 2014; Rantz et al. 2015). These nurses with a master's degree and training in extended clinical competencies are prepared to deliver care to vulnerable populations with complex health-care needs. In rural areas where shortages of primary care physicians are common, APNs are often the sole primary care provider for patients. Depending on US state legislature, APNs work independently or in collaboration with a physician. Within their specialty area, they assess, diagnose, and prescribe, managing the care of patients in its entirety, including referrals to physicians when indicated. In addition, they may also oversee other nursing home staff and provide training (Kane et al. 2003).

In the USA, the availability of a physician or APN for an on-site assessment of acute changes is considered a key strategy to reducing preventable hospitalizations (Ouslander et al. 2010). However, in Switzerland, access to a physician shows substantial regional variations. Patients living in regions with a high density of primary care physicians were less likely to be hospitalized due to an ACSC, whereas the risk was higher for patients living in rural areas (Berlin et al. 2014). Our results showing that more residents were admitted by ambulance for an ACSC $(42 \%)$ than for non-ACSCs $(31 \%)$, while it was the reverse for admission by a physician (ACSC: 46\%, non-ACSC: $59 \%$ ), may also reflect the issue of timely access to a primary care physician. Building a nursing home and primary care workforce with greater reliance on APNs, especially in rural areas where access to a primary care appointment may be delayed, could help reduce ACSC and associated costs in the Swiss health-care system.

Another important factor in reducing ACSCs is the implementation of advance care planning (ACP), which has been shown to increase the number of residents that die in the nursing home (Martin et al. 2016). ACP helps "ensure that people receive the medical care that is consistent with their values, goals and preferences during serious and chronic illness" (Sudore et al. 2017). This includes the appointment of a trusted person to make decisions on one's behalf, when decision-making is no longer possible. Switzerland has recently introduced a national strategy for care planning, centered on the importance of long-term care. It outlines advance care planning and recommends discussing possible future developments and scenarios for the current illnesses, including ACSCs, to assess resident preferences and plan interventions in case of exacerbations (Bundesamt für Gesundheit und palliative ch 2018). Such care plans might also include physician orders about PRN ("as needed") medications and documentation of wishes concerning treatment and hospitalization, which in turn supports care staff in managing acute situations when the physician is not immediately available, for example during nights and weekends.

Finally, it is important to note that programs taking a multifactorial approach have proven to be effective in reducing unnecessary hospitalizations. One such program is INTERACT, an intervention specifically designed to improve staff's ability in early identification of complications, interprofessional communication, advance care planning, the effective treatment of chronic conditions, and timely reaction to acute changes in condition (Ouslander et al. 2014). Its effectiveness depends on the implementation of the INTERACT tools (e.g., tools to improve communication), which show the importance of the nursing homes' motivation for change, since training and support alone will not reach the desired effect (Huckfeldt et al. 2018). Such programs are rare, and greater use should be explored to prevent hospitalizations in both the international and Swiss contexts.

The strength of the present study is the use of national data representing all Swiss hospitalizations, allowing us to 
provide a comprehensive description of nursing home hospitalizations. However, several limitations apply. First, the lists of conditions considered to be ambulatory care sensitive were developed in the USA and Canada and no corresponding structured expert rating was performed for the Swiss context. Although the main chronic conditions such as CHF, COPD, and pneumonia are at the forefront in ACSC lists, the inclusion of falls and trauma for nursing home residents may be controversial, since evidence for effective fall prevention is still scarce. Additionally, ACSCs provide a limited view on preventability and it is possible that not all ACSCs can be avoided in every case. In some instances, ACSCs might indicate a severe condition for which no early detection or advanced care planning could have avoided a hospitalization. Moreover, ACSCs do not take into account other system and patient level factors, such as treatment option availability in nursing homes, wishes of residents and relatives regarding hospitalizations, or residents' overall health status. Thus, our findings on ACSCs provide valuable insight into preventable hospitalizations in Switzerland. Additional studies are needed to better understand the intricacies of different factors that favor hospitalizations.

In conclusion, hospitalizations due to ACSCs in Switzerland are frequent and costly. In order to reduce preventable hospitalizations, a multifaceted approach is needed. This should include addressing timely access to primary care with an increased use of APN roles in nursing homes; promotion of advance care planning; strengthening geriatric expertise of nursing home staff including monitoring of chronic diseases, the early detection and treatment of exacerbating symptoms, fall prevention, and the support of interprofessional communication, among other factors. The recommendation for financial reimbursement for ACP conversations at the Swiss policy level is a welcome development (Bundesamt für Gesundheit und palliative ch 2018).

Funding The study received no funding.

\section{Compliance with ethical standards}

Conflict of interest The authors declare that they have no conflict of interest.

Ethical approval This article does not contain any studies with human participants or animals performed by any of the authors.

Open Access This article is distributed under the terms of the Creative Commons Attribution 4.0 International License (http://creative commons.org/licenses/by/4.0/), which permits unrestricted use, distribution, and reproduction in any medium, provided you give appropriate credit to the original author(s) and the source, provide a link to the Creative Commons license, and indicate if changes were made.

\section{References}

Ansari Z, Haider SI, Ansari H, De Gooyer T, Sindall C (2012) Patient characteristics associated with hospitalisations for ambulatory care sensitive conditions in Victoria, Australia. BMC Health Serv Res 12:1. https://doi.org/10.1186/1472-6963-12-475

Ashton T (2014) Hospitalizations of nursing homes residents: the role of reimbursement policies. Isr J Health Policy Res 3:3. https:// doi.org/10.1186/2045-4015-3-3

Axon RN, Gebregziabher M, Craig J, Zhang J, Mauldin P, Moran WP (2015) Frequency and costs of hospital transfers for ambulatory care-sensitive conditions. Am J Manag Care 21:51-59

Bakerjian D (2008) Care of nursing home residents by advanced practice nurses: a review of the literature. Res Gerontol Nurs 1:177-185. https://doi.org/10.3928/00220124-20091301-01

Berlin C, Busato A, Rosemann T, Djalali S, Maessen M (2014) Avoidable hospitalizations in Switzerland: a small area analysis on regional variation, density of physicians, hospital supply and rurality. BMC Health Serv Res 14:289. https://doi.org/10.1186/ 1472-6963-14-289

Billings J, Zeitel L, Lukomnik J, Carey TS, Blank AE, Newman L (1993) Impact of socioeconomic status on hospital use in New York City. Health Aff (Millwood) 12:162-173. https://doi.org/ 10.1377/hlthaff.12.1.162

Bindman AB et al (1995) Preventable hospitalizations and access to health care. JAMA 274:305-311

Boockvar K, Fishman E, Kyriacou CK, Monias A, Gavi S, Cortes T (2004) Adverse events due to discontinuations in drug use and dose changes in patients transferred between acute and long-term care facilities. Arch Intern Med 164:545-550. https://doi.org/10. 1001/archinte.164.5.545

Bundesamt für Gesundheit und palliative ch (2018) Gesundheitliche Vorausplanung mit Schwerpunkt «Advance Care Planning». Nationales Rahmenkonhept für die Schweiz. Bundesamt für Gesundheit, Bern

Bundesamt für Statistik Steckbrief—Erhebung. Medizinische Statistik der Krankenhäuser

Dwyer R, Gabbe B, Stoelwinder JU, Lowthian J (2014) A systematic review of outcomes following emergency transfer to hospital for residents of aged care facilities. Age Ageing 43:759-766. https:// doi.org/10.1093/ageing/afu117

Grabowski DC, O'Malley AJ, Barhydt NR (2007) The costs and potential savings associated with nursing home hospitalizations. Health Aff (Millwood) 26:1753-1761. https://doi.org/10.1377/ hlthaff.26.6.1753

Fallpauschalen in Schweizer Spitälern http://www.drgs.ch/fileadmin/ Grundlagen/Die_SwissDRG_AG/Broschuere_SwissDRG_d_A4. pdf

Huckfeldt PJ et al (2018) Degree of implementation of the interventions to reduce acute care transfers (INTERACT) quality improvement program associated with number of hospitalizations. J Am Geriatr Soc 66:1830-1837. https://doi.org/10.1111/ jgs. 15476

Kane RL, Keckhafer G, Flood S, Bershadsky B, Siadaty MS (2003) The effect of Evercare on hospital use. J Am Geriatr Soc 51:1427-1434. https://doi.org/10.1046/j.1532-5415.2003.51461. $\mathrm{x}$

Kirsebom M, Hedstrom M, Wadensten B, Poder U (2014) The frequency of and reasons for acute hospital transfers of older nursing home residents. Arch Gerontol Geriatr 58:115-120. https://doi.org/10.1016/j.archger.2013.08.002 
Kjelle E, Lysdahl KB (2017) Mobile radiography services in nursing homes: a systematic review of residents' and societal outcomes. BMC Health Serv Res 17:231. https://doi.org/10.1186/s12913017-2173-8

Martin RS, Hayes B, Gregorevic K, Lim WK (2016) The effects of advance care planning interventions on nursing home residents: a systematic review. J Am Med Dir Assoc 17:284-293. https:// doi.org/10.1016/j.jamda.2015.12.017

McAndrew RM, Grabowski DC, Dangi A, Young GJ (2015) Prevalence and patterns of potentially avoidable hospitalizations in the US long-term care setting. Int $\mathrm{J}$ Qual Health Care 28:104-109. https://doi.org/10.1093/intqhe/mzv110

Mcandrew RM, Grabowski DC, Dangi A, Young GJ (2016) Prevalence and patterns of potentially avoidable hospitalizations in the US long-term care setting. Int $\mathrm{J}$ Qual Health Care 28:104-109. https://doi.org/10.1093/intqhe/mzv110

Millman M (1993) Access to health care in America. National Academies Press, Washington

OECD (2015) Health at a glance 2015: OECD indicators. OECD Publishing, Paris

Ouslander JG, Maslow K (2012) Geriatrics and the triple aim: defining preventable hospitalizations in the long-term care population. J Am Geriatr Soc 60:2313-2318. https://doi.org/10. 1111/jgs. 12002

Ouslander JG et al (2010) Potentially avoidable hospitalizations of nursing home residents: frequency, causes, and costs. J Am Geriatr Soc 58:627-635. https://doi.org/10.1111/j.1532-5415. 2010.02768.x

Ouslander JG, Bonner A, Herndon L, Shutes J (2014) The interventions to reduce acute care transfers (INTERACT) quality improvement program: an overview for medical directors and primary care clinicians in long term care. J Am Med Dir Assoc 15:162-170. https://doi.org/10.1016/j.jamda.2013.12.005

Palese A et al (2016) Hospital-acquired functional decline in older patients cared for in acute medical wards and predictors: findings from a multicentre longitudinal study. Geriatr Nurs 37:192-199. https://doi.org/10.1016/j.gerinurse.2016.01.001

Purdy S, Griffin T, Salisbury C, Sharp D (2009) Ambulatory care sensitive conditions: terminology and disease coding need to be more specific to aid policy makers and clinicians. Public Health 123:169-173. https://doi.org/10.1016/j.puhe.2008.11.001

Rantz MJ et al (2015) Better care, better quality: reducing avoidable hospitalizations of nursing home residents. J Nurs Care Qual 30:290-297. https://doi.org/10.1097/ncq.0000000000000145

Renom-Guiteras A, Uhrenfeldt L, Meyer G, Mann E (2014) Assessment tools for determining appropriateness of admission to acute care of persons transferred from long-term care facilities: a systematic review. BMC Geriatr 14:80. https://doi. org/10.1186/1471-2318-14-80

Sudore RL et al (2017) Defining advance care planning for adults: a consensus definition from a multidisciplinary delphi panel. J Pain Symptom Manage 53:821-832.e821. https://doi.org/10. 1016/j.jpainsymman.2016.12.331

SwissDRG AG (2012) Fallpauschalen-Katalog SwissDRG-Version 2.0. Bern

Vlaeyen E et al (2015) Characteristics and effectiveness of fall prevention programs in nursing homes: a systematic review and meta-analysis of randomized controlled trials. J Am Geriatr Soc 63:211-221. https://doi.org/10.1111/jgs.13254

Walker JD, Teare GF, Hogan DB, Lewis S, Maxwell CJ (2009) Identifying potentially avoidable hospital admissions from Canadian long-term care facilities. Med Care 47:250-254. https://doi.org/10.1097/MLR.0b013e3181847588

Walsh EG, Freiman M, Haber S, Bragg A, Ouslander J, Wiener JM (2010) Cost drivers for dually eligible beneficiaries: Potentially avoidable hospitalizations from nursing facility, skilled nursing facility and home and community-based services waivers programs. Final task 2 report. RTI International, Waltham, MA

Walsh EG, Wiener JM, Haber S, Bragg A, Freiman M, Ouslander JG (2012) Potentially avoidable hospitalizations of dually eligible Medicare and Medicaid beneficiaries from nursing facility and home- and community-based services waiver programs. J Am Geriatr Soc 60:821-829. https://doi.org/10.1111/j.1532-5415. 2012.03920.x

Weissman JS, Gatsonis C, Epstein AM (1992) Rates of avoidable hospitalization by insurance status in Massachusetts and Maryland. JAMA 268:2388-2394

WHO Regional Office for Europe (2016) Assessing health services delivery performance with hospitalizations for ambulatory care sensitive conditions. WHO Regional Office for Europe, Copenhagen

Xing J, Mukamel DB, Temkin-Greener H (2013) Hospitalizations of nursing home residents in the last year of life: nursing home characteristics and variation in potentially avoidable hospitalizations. J Am Geriatr Soc 61:1900-1908

Zisberg A, Sinoff G, Agmon M, Tonkikh O, Gur-Yaish N, Shadmi E (2016) Even a small change can make a big difference: the case of in-hospital cognitive decline and new IADL dependency. Age Ageing 45:500-504. https://doi.org/10.1093/ageing/afw063

Publisher's Note Springer Nature remains neutral with regard to jurisdictional claims in published maps and institutional affiliations. 